\title{
EL CONTROL EN LAS ASAMBLEAS AUTONÓMICAS A TRAVÉS DE LOS CIUDADANOS*
}

\author{
ASCENSIÓN ELVIRA PERALES \\ Profesora Titular de Derecho Constitucional \\ Universidad Carlos III de Madrid
}

\author{
SUMARIO \\ I. Introducción. \\ II. Las preguntas de iniciativa ciudadana. \\ III. El derecho de petición. \\ IV. Conclusiones.
}

\section{INTRODUCCIÓN}

El control parlamentario ha sufrido una larga evolución desde los primeros parlamentos liberales en los que cualquier moción podía llegar a derivar en una dimisión gubernamental a las técnicas del parlamentarismo racionalizado que en la práctica impiden que prospere una moción de censura, de forma tal que los clásicos medios de control que servían para poner en juego la responsabilidad política del gobierno - mociones de censura y de confianza- se han convertido en instrumentos para potenciar al propio gobierno o como medio de lucimiento (o intento de tal) por parte de los líderes políticos. En estas circunstancias cobran fuerza como instrumentos de control otros medios, que sin afectar a la responsabilidad gubernamental, tratan de fiscalizar la política del gobierno ya desde el prisma del parlamento ya desde el programa del propio gobierno.

Estos medios - preguntas, interpelaciones y comisiones de investigaciónhan querido contemplarse por algunos como meros instrumentos de información, pero suponen mucho más que eso, puesto que su finalidad no acaba con

* Este artículo tiene su origen en el marco del proyecto financiado por el Ministerio de Ciencia y Tecnología (cofinanciado con fondos FEDER), Referencia: BSO2003-06386. 
la recepción de la información solicitada, sino que la misma se encamina a fiscalizar la política gubernamental.

En los medios de control de los parlamentos autonómicos, al igual que en toda su actividad, en sus inicios se limitó a establecer una copia de los métodos y procedimientos utilizados en el Congreso de los Diputados. Ese mimetismo resultaba lógico ante la falta de experiencia democrática en nuestro país y ante la falta escasez de modelos en el Derecho comparado. Con el transcurso del tiempo esas asambleas autonómicas van poco a poco desarrollando nuevos modelos ajustados a sus características y necesidades, modelos que, a su vez, van trasladándose de unos reglamentos a otros.

Las asambleas autonómicas, por sus características, deberían ser terreno abonado para probar nuevos modos de participación parlamentaria, tanto hacia el interior como hacia el exterior, puesto que, en primer lugar, el número de parlamentarios es bastante reducido y, en segundo lugar, la población es también bastante menor. Ambos factores deberían de propiciar modelos más ágiles, menos rígidos, en los que fuera posible una participación más directa tanto de diputados como de ciudadanos, en los que la disciplina de partido no estuviera siempre presente y que reflejaran, en definitiva, el sentir de los ciudadanos.

Entre las fórmulas que recogen algunos parlamentos autonómicos hay dos que merecen que centremos nuestra atención: por un lado, las preguntas de iniciativa ciudadana, un claro intento de acercar a los ciudadanos a sus asambleas; por otro, un derecho clásico que merece una atención renovada: el derecho de petición. Ambos pueden convertirse en nuevos instrumentos de control parlamentario.

\section{PREGUNTAS DE INICIATIVA CIUDADANA}

Este tipo de preguntas constituyen una innovación interesante presente, de momento, en los reglamentos de tres parlamentos autonómicos: art. 165 del andaluz ${ }^{1}$,

1 Artículo 165. 1. Los andaluces y el resto de los ciudadanos residentes en Andalucía, o las personas jurídicas con domicilio o establecimiento permanente en la Comunidad Autónoma, podrán formular preguntas para su respuesta oral al Consejo de Gobierno o a cada uno de sus miembros. 2. Las preguntas se presentarán por escrito en le Registro General del Parlamento, y deberán contener los requisitos de identificación previstos en el artículo 70 del la Ley del Régimen Jurídico de las Públicas y del Procedimiento Administrativo Común. 3. Tras su examen, la Mesa del Parlamento ordenará su traslado a los Grupos parlamentarios si cumplen los requisitos de admisibilidad previstos en este Reglamento para igual tipo de iniciativas. 4. Para que estas preguntas puedan tramitarse en el pleno o en Comisión, deberán ser asumidas por algún Diputado, quien lo comunicará a la Mesa de la Cámara. Si fueran varios los Diputados que desearan formular una misma pregunta de este tipo se le asignará al primer Diputado que manifieste su intención de hacerlo. 5. La decisión de formularla en Pleno o en Comisión corresponderá al Diputado que le ha sido asignada. En todo caso, el diputado, al inicio de su intervención, hará constar el autor o autores de la iniciativa, y en su formulación no podrá modificar en lo sustancial el contenido originario del texto. 6. En cada sesión plenaria sólo podrá formularse un máximo de cuatro de estas preguntas, y su inclusión en el orden del día respectivo consume cupo. 7. Será de aplicación a estas iniciativas el régimen de caducidad anual previsto en el artículo 191 de este Reglamento. 
art. 172 del canario ${ }^{2}$ y art. 178 del murciano ${ }^{3}$. La primera en implantarlas fue la comunidad andaluza, sumándose después Murcia y Canarias. Aunque la regulación es bastante similar encontramos algunas diferencias de funcionamiento.

\section{II.1. Titulares}

En Andalucía se establece que el derecho lo tendrán los ciudadanos residentes en esa Comunidad y las personas jurídicas con domicilio o establecimiento permanente en la CA (art. 165.1 RPAnd). En Canarias corresponderá igualmente a cualquier ciudadano residente en Canarias, sin que se mencione a personas jurídicas (art. 172.1 RPCanar). Mientras que en el Reglamento murciano se abre a cualquier ciudadano y a "cualquier persona jurídica que represente intereses sociales" (art. 178.1).

2 Artículo 172. 1. Cualquier ciudadano residente en Canarias podrá formular preguntas para su respuesta oral al Gobierno o a cada uno de sus miembros. 2. Las preguntas se presentarán por escrito en el Registro General del Parlamento de Canarias, debiendo contener los requisitos de identificación que se prevén en la Ley del régimen jurídico de las administraciones públicas. 3. Una vez examinadas por al Mesa de la Cámara, y de ser admitidas si cumplen los requisitos que se exigen en el presente capítulo a las demás preguntas, aquélla ordenará su traslado a los distintos grupos parlamentarios. 4. Sólo podrán tramitarse aquellas preguntas que sean asumidas por un diputado, para lo cuál éste habrá de comunicarlo por escrito a la Mesa de la Cámara. De ser varios los diputados que desearan asumir la pregunta, se le asignará a aquél que primero manifieste fehacientemente su intención de hacerlo. 5. Las preguntas admitidas a trámite por la Mesa de la Cámara que no hayan sido asumidas por ningún diputado en el plazo de quince días desde la fecha de su admisión se considerarán decaídas, no pudiendo ser objeto de tramitación ni en Pleno ni en Comisión. 6. La decisión sobre si una pregunta de iniciativa popular se tramita en Pleno o en comisión corresponde al diputado que la haya asumido aunque, en todo caso, éste habrá de hacer constar en su intervención el autor de la iniciativa, salvo que expresamente éste haya solicitado permanecer en el anonimato haciéndolo constar en su escrito de presentación. Asimismo, el diputado no podrá modificar de forma sustancial en su intervención el contenido originario del texto de al pregunta. 7. En cada sesión plenaria sólo podrán formularse dos preguntas de este tipo como máximo. Para su inclusión en el orden del día se tendrá en cuenta como criterio prioritario el orden cronológico de su presentación, sin perjuicio de que éste pueda ser alterado por razones de urgencia o de actualidad, cuando la materia sobre la que versa la pregunta así lo aconseje. 8. Finalizado un periodo de sesiones, las preguntas de iniciativa popular asumidas dentro de plazo por un diputado que no hayan podido ser sustanciadas en Pleno Comisión, se tramitarán como preguntas con respuesta por escrito.

3 Artículo 178. 1. Cualquier persona jurídica que represente intereses sociales y actúe legítimamente a través de sus órganos, y cualquier ciudadano con su firma y mención de su documento nacional de identidad, podrán dirigir preguntas a la Asamblea Regional con el ruego de que sean formuladas al Consejo de Gobierno.2. La Mesa de la Cámara se pronunciará sobre la admisibilidad de cada una de ellas, rechazando de forma motivada, pero sin posible recurso, las que considere improcedentes. 3. Una vez admitida una pregunta, quedará depositada en la Secretaría General de la Asamblea, donde cualquier Diputado podrá asumirla, convirtiéndola en pregunta con respuesta escrita u oral. Al formularla deberá mencionarse siempre su origen, aunque preservando, si se tratare de una persona física, el nombre y apellidos del firmante. 4. Las preguntas admitidas por la Mesa y no asumidas por ningún Diputado en los quince días siguientes a su anuncio en el Boletín Oficial de la Asamblea Regional, se considerarán rechazadas. 
En las tres comunidades, pues, el derecho se reserva, en el caso de personas naturales, a los ciudadanos, exigiéndose el requisito de la residencia en el caso de Andalucía y Canarias, mientras que en Murcia al no especificarse cabría entender que se extiende a cualquier ciudadano, resida o no en esa Comunidad. La utilización del término ciudadano indica la persona con pleno ejercicio de sus derechos políticos, lo cual conlleva la exigencia de la mayoría de edad.

Por otra parte, con el término ciudadano parece excluirse a los extranjeros, lo que tiene su sentido al vincularse la actividad de las Asambleas legislativas autonómicas con el derecho de participación política del art. $23 \mathrm{CE}$, que se reserva a los nacionales salvo, en relación con el art. 13.2 CE, el derecho de sufragio activo y pasivo en las elecciones municipales. No obstante, consideramos debería ampliarse esa facultad a los extranjeros, al menos a los residentes. El hecho de que para ejercer el sufragio activo y pasivo para estos parlamentos se exija la ciudadanía española, no significa que no pueda extenderse a esta participación que son las preguntas ciudadanas (a pesar de la denominación), máxime tendiendo en cuenta el requisito exigido de la intermediación de un diputado en la formulación de la pregunta. No obstante, cabría interpretar que, si en el caso de los ciudadanos las preguntas ciudadanas se englobarían dentro de los derechos de participación política, en el caso de los extranjeros se las considerara como ejercicio de un derecho ordinario.

En relación con las personas jurídicas, como hemos expuesto, cada Comunidad ha optado por una respuesta diferente: en Canarias no se menciona esa posibilidad con lo que la interpretación más acorde parece la de considerar que únicamente las personas físicas están legitimadas para plantear este tipo de preguntas. Las otras dos comunidades si admiten las posibilidad de preguntas planteadas por personas jurídicas, pero con un diferente alcance: en Murcia de manera más restrictiva al exigir que 'represente intereses sociales', con una definición, pues, que provoca una cierta inseguridad jurídica en cuanto a su alcance, pues no se sabe si con esa expresión quiere decir intereses sociales relevantes o simplemente que sus intereses no tengan un carácter meramente particular. Por otra parte deja la duda de si lleva aparejado o, al menos, facilita, las preguntas formuladas por determinadas entidades a las que el ordenamiento confiere especial relevancia social, como pudieran ser sindicatos, asociaciones de utilidad pública, fundaciones u ONGs ${ }^{4}$. En cualquier caso, la precisión parece indicar una voluntad de restringir las preguntas propuestas por personas jurídicas en general o, desde otro punto de vista, favorecer las formuladas por personas jurídicas a las que se presuma el citado interés social (¡cómo si eso fuera evidente!).

En Andalucía, por el contrario, la posibilidad de que formulen preguntas personas jurídicas se plantea con una fórmula generosa, dado que basta que

4 Resultaría más dudoso en el caso de partidos políticos, pues, en este caso, si cuentan con representación parlamentaria, parece que ese sería el cauce natural para formular preguntas. En caso de no contar con dicha representación cabría plantear su grado de relevancia y, de carecer de ella, quizás también su representación de 'intereses sociales'. En este caso se plantea también la indeterminación de la formulación reglamentaria. 
tengan domicilio o establecimiento en la Comunidad, de tal forma que si la ubicación es lo que determina el nexo con la Comunidad, deja la puerta abierta para personas jurídicas extranjeras, siempre que cumplan con el requisito exigido 5 .

Creemos, por último, que, en principio no tendrían cabida las preguntas de personas jurídicas públicas, pues esas tienen otros cauces de comunicación con el resto de los poderes públicos; no obstante, cabría abrir una posibilidad, como excepción, en aquellos supuestos en los que las preguntas estén vinculadas con la actividad propia de las mismas y cuando no haya sido posible obtener respuesta por otros cauces. Piénsese, por ejemplo, en supuestos en los que la Universidad o un municipio formularan una pregunta relacionada con su autonomía. En cualquier caso esta posibilidad la planteamos con todas las cautelas.

\section{II.2. Procedimiento}

Las preguntas se presentarán en el Registro del Parlamento con plena identificación del solicitante, en el caso de las personas jurídicas con identificación, entendemos de la propia persona jurídica así como de su representante. En Andalucía en este último caso deberá justificar su sede en la Comunidad y, en el caso de Murcia debería, a su vez, justificar la representación de un interés social, salvo, quizás, que se desprenda directamente del propio carácter de la persona.

En Andalucía se establece que, tras la comprobación de que siguen los requisitos exigidos, la Mesa dará traslado a los Grupos parlamentarios (art. 165.3 RPAnd). Para su tramitación necesitará de la asunción por algún diputado, quien decidirá si la formula ante el Pleno o ante una comisión. El Diputado, en todo caso, deberá manifestar al autor de la pregunta y mantener sustancialmente su contenido (art. 165.4 y 5 RPAnd). Su caducidad será anual en Andalucía (art. 165.7 RPAnd).

En la Asamblea de Murcia, la Mesa se pronunciará sobre la admisibilidad, pudiendo rechazarlas de forma motivada. En Andalucía se establece igualmente un trámite de admisión por la Mesa. Si el objeto de la pregunta coincide con otra que se hubiera formulado durante el mismo periodo de sesiones, se inadmitirá, facilitándose a la persona copia de la respuesta anteriormente proporcionada (art. 167.2).

En todos los casos, el trámite de examen de las preguntas ciudadanas y su correspondiente admisión entendemos que se trata de un mero examen formal, similar al que se efectúa en relación con las preguntas formuladas por los diputados, es decir comprobar que se corresponde con el contenido de una

5 Parece chocar esa amplia posibilidad de que las personas jurídicas puedan plantear estas preguntas con la restricción de esa facultad para las personas naturales al limitarlas a los ciudadanos. 
pregunta parlamentaria, en mayor o menor medida expresado en el correspondiente reglamento y que no se dan ninguno de los motivos de rechazo.

Con respecto al contenido de las preguntas, suele establecerse que no se admitirán las de exclusivo interés personal de quien la formula ni de otra persona singularizada, ni las que supongan consultas de índole estrictamente jurídica (por ejemplo, art. 159.2 RPAnd), igualmente no se admitirán aquellas que contengan términos ofensivos ${ }^{6}$. A ello habría que añadir que la pegunta se enmarque dentro de las competencias de la comunidad autónoma respectiva o esté vinculada con ellas. En consecuencia, si no se dan ninguno de estos supuestos, la mesa tendría que admitir la pregunta.

En Murcia, una vez admitida la pregunta, quedará depositadas en la Secretaría general de la Asamblea, donde cualquier Diputado podrá asumirla, "convirtiéndola en pregunta con respuesta escrita u oral" (art. 178.3 RPMur). "LL]as preguntas admitidas por la Mesa y no asumidas por ningún Diputado en los quince días siguientes a su anuncio en el Boletín Oficial de la Asamblea Regional, se considerarán rechazadas" (art. 178.4 RPMur). Aunque se señala que deberá manifestarse su origen, no obstante se establece que si la pregunta procede de una persona física se preservará su identidad (art. 178.3 RPMur). Particularmente, entendemos que esa preservación de la identidad debería producirse únicamente cuando así lo solicitara el firmante y no con carácter general.

En Andalucía, tras la admisión, se dará traslado a los Grupos parlamentarios (se entiende que para su conocimiento), debiendo igualmente ser asumidas por un Diputado para que sean tramitadas. Éste deberá hacer constar al autor o autores de la iniciativa.

En el Parlamento andaluz se señala que el régimen de caducidad será anual.

En Canarias también deberán se asumidas por un diputado, pudiendo tramitarse tanto en pleno como en comisión (art. 172.4), decayendo si no se ha producido tal asunción en un plazo de quince días (art. 172.5). Se deberá hacer constar al autor de la iniciativa, salvo que éste haya solicitado permanecer en el anonimato en su escrito de presentación (art. 172.6 RPCanar), lo cual parece la solución más lógica.

En cada sesión del Parlamento andaluz podrán formularse un máximo de cuatro de estas preguntas (art. 165.6 RPAnd). En Canarias se indica un número máximo de dos (art. 172.7 RPCanar)

La caducidad establecida en el Reglamento andaluz parece más adecuada que la estipulada en Murcia o Canarias, pues quince días parece un plazo muy corto y que puede conducir a que no sea asumida por ningún Diputado si, por ejemplo, en el periodo en cuestión prima algún tema candente para la Comunidad o se ha producido alguna crisis.

6 Todos los Reglamentos contienen alguna disposición en la que se estipula que se rechazarán aquellas preguntas que contengan palabras o viertan conceptos ofensivos al decoro de la Cámara, de sus miembros, de las instituciones públicas o de cualquier otra persona o entidad (por ejemplo, art. 103 RPAnd en relación con el art. 167). 


\section{3. ¿RECURSO DE AMPARO?}

Cabe plantearse si cabe el recurso de amparo en relación con este tipo de preguntas. La respuesta creemos que ha de ser afirmativa; es más, en su caso, hay dos momentos en los que cabría la posibilidad de plantear el recurso de amparo. Un primer momento sería el del rechazo, por parte de la Mesa, de aceptar la pregunta planteada de acuerdo con los requisitos expresados en el Reglamento de la Cámara respectiva. Otra, la del rechazo una vez asumida por un diputado, igualmente en un caso en el que la asunción se hubiera efectuado de acuerdo con el Reglamento parlamentario.

En primer lugar, hay que recordar que el derecho de participación política es un derecho de configuración legal, por lo tanto, el catálogo de supuestos de participación no es un catálogo cerrado sino, por el contrario, abierto a los sistemas de participación que pueda arbitrar el legislador, lo cual obviamente engloba las posibilidades de participación recogidas en los reglamentos parlamentarios, normas, no olvidemos, con rango de ley y con reserva material y que, de hecho, recogen las formas de participación de los diputados. Por lo tanto, los reglamentos son las normas idóneas para incluir nuevas fórmulas de participación en su seno.

En efecto, en primer lugar, el art. 23 CE se refiere a la participación de los ciudadanos directamente o por medio de representantes, en este supuesto se trataría de una especie de participación mixta, de modo que, por una parte, el ciudadano participa por medio de su pregunta y, por otra, para perfeccionarse el acto necesita de la concurrencia de un representante elegido. El primer requisito, la admisión por parte de la Mesa es todavía el ciudadano el que está directamente involucrado por lo que será éste el que pueda presentar un amparo frente al derecho que se le vulnera. Por otra parte, el art. 42 LOTC sólo habla de la posibilidad de plantear amparo frente a actos sin valor de ley de, en lo que aquí nos interesa, las asambleas legislativas de las Comunidades Autónomas o de sus órganos, de tal forma que la legitimación activa seguirá siendo la general de los amparos, es decir cualquier persona que invoque un interés legítimo (art. 162. 1 b) $)^{7}$.

Los Reglamentos parlamentarios se refieren a 'ciudadanos' por lo que, en relación con este derecho en particular y, salvo modificaciones futuras, hay que entenderlo como un derecho reservado a los nacionales con pleno disfrute de sus derechos políticos. No obstante, en el caso en que se abriera el ejercicio de esta facultad a extranjeros habría que plantarse si también ellos estarían legitimados para, en su caso, plantear un recurso de amparo. Hay que partir de que

7 Aunque también tengan legitimación para presentar un recurso de amparo el Defensor del Pueblo y el Ministerio Fiscal, creemos que en este caso, no podrían o no deberían ejercer esa potestad, debido al carácter singular de la participación política, en la que parece existir un carácter personalísimo del interés en juego. En pura hipótesis sólo se nos ocurre una posibilidad de intervención en un caso de flagrante vulneración del reglamento parlamentario y ante una persona desvalida, que utilizara este medio como forma de hacer valer sus derechos. 
el TC ha indicado que son también sujetos de derechos fundamentales, no obstante ha establecido diversos tipos de situaciones en los que los extranjeros se encuentran en relación con los derechos fundamentales, por una parte, aquellos que pertenecen a todas las personas, por otra aquellos que pueden presentar limitaciones para los extranjeros que no compartan los nacionales y finalmente aquéllos que son exclusivos de los nacionales ${ }^{8}$. En este grupo se sitúa el derecho de participación en los asuntos públicos, pues, primero, el art. 23 CE se refiere sólo a 'ciudadanos' y, segundo, el art. 13.2 CE los reserva igualmente a los nacionales, salvo en lo que se refiere al derecho de sufragio activo y pasivo en las elecciones municipales. En consecuencia, de acuerdo con lo que manifestamos anteriormente, si entendemos que no existe tal derecho fundamental para los extranjeros, no cabría la formulación de un recurso de amparo, sin perjuicio del derecho que tendría el diputado que hubiera asumido la pregunta, si fuera una vez asumida cuando se produjera la vulneración del derecho.

Se plantearían dudas sobre la posibilidad de que pudieran plantear recurso de amparo personas jurídicas.

En efecto, en relación con la posibilidad de que planteara un recurso una persona jurídica nos encontramos con el carácter personalísimo de la participación política que ha acentuado la interpretación del Tribunal Constitucional y que se deriva de las SSTC 5 y 10/1983, lo que ha llevado, incluso a limitar los supuestos en los que cabe la posibilidad de planteamiento de recursos por parte de los partidos políticos.

Caso aparte, no obstante, sería el supuesto de una pregunta planteada por una persona jurídica pública, en este punto habría que considerar que si se dan las condiciones para que pudiera plantearla, posiblemente también habría que admitir la posibilidad de planteamiento de un recurso de amparo.

En el supuesto de vulneración del derecho de un particular el procedimiento sería también el del art. 42 LOTC, es decir, el recurso se plantearía directamente ante el TC, puesto que si bien este tipo de acceso directo se pensó en relación con la actividad parlamentaria clásica, lo que permite es el control de los interna corporis acta parlamentarios y se trata de ese tipo de acto tanto si afecta a un diputado (o senador) como si, como es este caso, afecta a un ciudadano. En ambos casos se trata de vulneración de un derecho fundamental y en ambos de control de actos propios de la actividad parlamentaria. Que el constituyente y el legislador orgánico no tuvieran en mente (por no existir el procedimiento con anterioridad) el supuesto no cierra la vía a que se plantee en igual medida, dado que comparte los requisitos genéricamente exigidos.

Con respecto a la posibilidad de que sea el parlamentario el que presente recurso de amparo, en este caso, será de acuerdo con las reglas generales para este tipo de casos, es decir en supuestos en los que la Mesa niegue en contra de las normas reglamentarias la posibilidad de formular la pregunta o le prohíba

8 Véanse, por ejemplo, SSTC 99/1985 o 107/1984. 
hacerlo en los términos en los que venía expuesta (siempre que estos fueran, obviamente, conformes al Derecho parlamentario). Esto significará, a su vez, que siempre que se den esos supuestos podrá elevarse el amparo, sin importar aquí ya de quién procediera originariamente la pregunta, es decir en estos casos cabrá el amparo con independencia de que la pregunta hubiera sido efectuada por un nacional o un extranjero, por una persona natural o jurídica. En estos casos ya es el parlamentario el que asume la participación y el que tiene plena capacidad para denunciar una vulneración del derecho de participación política.

En cualquiera de los dos supuestos habrá que tener en cuenta la doctrina del Tribunal Constitucional acerca del control por parte de la Mesa de las preguntas parlamentarias y de esta forma distinguir entre aquellos supuestos en los que se establece un control meramente formal de los casos en los que cabe un control también material. Así, en el segundo caso, sólo cabrá un control "exclusivamente en cuanto resulte determinante para llevar a cabo el juicio de calificación sobre la idoneidad y procedencia del procedimiento parlamentario elegido para sustanciar la iniciativa deducida y para pronunciarse sobre su admisión o no a trámite, si respeta o no los límites o condiciones materiales que el Reglamento establece, bien con carácter general respecto a los escritos y documentos de índole parlamentaria, bien con carácter específico, para las preguntas" (STC 107/2001, de 23 de abril, en relación con la Asamblea de Murcia, FF.JJ. 4 y 5). Para precisar en otro caso que «al decidir la Mesa sobre la admisión no podrá en ningún caso desconocer que los actos a que venimos refiriéndonos son manifestación del ejercicio de un derecho del parlamentario que los formula y que, por ello, cualquier rechazo arbitrario o no motivado causará lesión de dicho derecho y, a su través, según hemos indicado, del fundamental del Diputado a desarrollar sus funciones sin impedimentos ilegítimos (art. 23.2 CE), (STC 177/2002, de 14 de octubre, F.J.3). En esta última, aunque se refiere a la figura del diputado, habrá que considerar que el argumento sería trasladable a la participación ciudadana, cuando ésta viene reconocida, y, por supuesto, al diputado que asume una pregunta ciudadana. En cualquiera de los casos, habrá que considerar que regirá el principio general de interpretar el derecho siempre sobre la base de que cualquier duda deberá resolverse en la forma más favorable para su ejercicio.

En otro orden de cosas, conviene precisar que en el ejercicio de este derecho siempre habrá de garantizarse la indemnidad del que efectúa la pregunta, de forma similar a como acontece con el derecho de petición, pues en otro caso podría verse afectada una persona por haber ejercido un derecho reconocido al haber podido incomodar a algún poder público, luego los órganos jurisdiccionales (o cualquier otro poder público) estarían obligados, en su caso, a reparar el daño ocasionado por un motivo semejante?

9 Por sólo poner un ejemplo: no resulta inimaginable que a un ciudadano que hubiera preguntado por la adjudicación de plazas en un centro de enseñanza público, la autoridad responsable, incómoda, negara el acceso al mismo de sus hijos. 
Entendemos que en virtud de las limitaciones impuestas a las preguntas no cabe vulneración del derecho al honor (o de algún otro derecho), pues, en ese caso, tendría que inadmitirse la pregunta. En caso de algún otro tipo de extralimitación, cabría la reformulación de la pregunta por parte del diputado que la hubiera asumido.

El fallo, obviamente, será idéntico al general. El problema práctico vendrá de que si la resolución se produce al cabo de bastante tiempo, como es habitual, sólo tendrá efectos declarativos. En otro caso obligaría a admitir la pregunta y a que siguiera el resto del proceso: asunción, en su caso, por parte de un parlamentario o planteamiento ya de la pregunta si el rechazo se hubiera producido una vez asumida por aquél.

En torno a la reforma de LOTC quizá la dificultad sea la de la relevancia constitucional. En este supuesto sí cabe imaginar una primera respuesta de reconocer la relevancia del procedimiento con independencia del contenido de la pregunta.

\section{4. LA PRÁCTICA DE LAS PREGUNTAS CIUDADANAS}

En Murcia y en Canarias es todavía escasa la experiencia con este tipo de preguntas, pues es sólo la VI legislatura cuando han comenzado a implantarse. Así hasta 20 de junio de 2005 en Murcia se habían formulado 12 preguntas a iniciativa popular y en Canarias 43, de las que 5 fueron rechazadas, una archivada y otra retirada. En Andalucía este tipo de iniciativa ciudadana se inició en la IV legislatura, habiéndose presentado en ella 16, 102 en la V y 32 en la VI. En la V legislatura, en particular, 19 fueron objeto de respuesta en Comisión y 15 de respuesta en Pleno, el número de preguntas no admitidas por la Mesa fue muy bajo (5), pero el resto de las preguntas decayeron; en la VI el número de preguntas decaídas fue de 5 y dos no fueron admitidas. Llama la atención que fuera sensiblemente menor el número de preguntas en las VI que en la V legislatura, cuando parece que su número tendería a incrementarse a medida que este instrumento fuera siendo más conocido. En la VII legislatura hasta el mes octubre de 2006 se habían presentado 41 preguntas ciudadanas.

En líneas generales puede comprobarse como las preguntas ciudadanas suelen versar sobre temas cercanos a los ciudadanos: salud, urbanismo y medio ambiente o educación ${ }^{10} \mathrm{y}$, en este sentido, entendemos que más allá de la eficacia que la pregunta en sí pueda desplegar, puede servir a los diputados para conocer las inquietudes de sus conciudadanos y ayudarles, en su caso, a adoptar las medidas oportunas.

Desde el punto de vista cuantitativo este tipo de preguntas, resulta insignificante frente a las preguntas de los Diputados, tanto de respuesta oral, como

10 No obstante se encuentran preguntas sobre las cuestiones más variadas, algunas incluso aparentemente alejadas de las competencias autonómicas, como una pregunta (admitida a trámite por la Mesa) en el Parlamento andaluz sobre la retirada de tropas de Irak (Expediente: 7-04/PIC-000007). 
de respuesta escrita. Por citar sólo un caso, el de la Comunidad con más experiencia en este campo, Andalucía, en la VI legislatura se formularon por los diputados 12.062 preguntas escritas, 1899 preguntas de repuesta oral en Comisión y 1709 de respuesta en el Pleno, con lo que las 32 preguntas ciudadanas quedan absolutamente diluidas en el océano de las preguntas tradicionales.

\section{DERECHO DE PETICIÓN}

Entre los derechos de participación suele incluirse el derecho de petición, derecho que, aunque incluido entre los derechos fundamentales, ocupa un lugar secundario en la actualidad, hecho que ha llevado a que fuera muy tardio su desarrollo estatal ${ }^{11}$. En palabras del Tribunal Constitucional "La petición en que consiste el derecho en cuestión tiene un mucho de instrumento para la participación ciudadana aun cuando lo sea por vía de sugerencia, y algo del ejercicio de la libertad de expresión como posibilidad de opinar ${ }^{12}$ (STC 243/1993, de 15 de julio). Encontrando en la misma Sentencia la mejor definición del contenido y efectos: "el contenido de este derecho como tal es mínimo y se agota en la mera posibilidad de ejercitarlo, formulando la solicitud sin que de ello pueda derivarse perjuicio alguno al interesado, garantía o cautela que está en el origen histórico de este derecho y ha llegado a nuestros días. Ahora bien, hoy el contenido comprende algo más, aun cuando no mucho más, e incluye la exigencia de que el escrito al cual se incorpore la petición sea admitido, le dé el curso debido o se reexpida al órgano competente si no lo fuera el receptor y se tome en consideración. Desde la perspectiva del destinatario, se configuran dos obligaciones, una al principio, exteriorizar el hecho de la recepción, y otra al final, comunicar al interesado la resolución que se adopte (arts. 6.2 y 11.3 de la Ley reguladora), sin que ello "incluya el derecho a obtener respuesta favorable a lo solicitado" (STC 161/1988 y en el mismo sentido ATC 749/1985)".

Partiendo del hecho de que este derecho puede ejercerse ante cualquier poder público, algunos reglamentos de asambleas de Comunidades Autónomas

11 Ley Orgánica 4/2001, de 12 de noviembre, del derecho de petición.

12 En la misma Sentencia precisaba: "Concepto residual, pero no residuo histórico, cumple una función reconocida constitucionalmente, para individualizar la cual quizá sea más expresiva una delimitación negativa. En tal aspecto excluye cualquier pretensión con fundamento en la alegación de un derecho subjetivo o un interés legítimo especialmente protegido, incluso mediante la acción popular en el proceso penal o la acción pública en el contencioso-contable o en el ámbito del urbanismo. La petición en el sentido estricto que aquí interesa no es una reclamación en la vía administrativa, ni una demanda o un recurso en la judicial, como tampoco una denuncia, en la acepción de la palabra ofrecida por la Ley de Enjuiciamiento Criminal o las reguladoras de la potestad sancionadora de la Administración en sus diversos sectores. La petición, en suma, vista ahora desde su anverso, puede incorporar una sugerencia o una información, una iniciativa, "expresando súplicas o quejas", pero en cualquier caso ha de referirse a decisiones discrecionales o graciables (STC 161/1988), sirviendo a veces para poner en marcha ciertas actuaciones institucionales, como la del Defensor del Pueblo o el recurso de inconstitucionalidad de las Leyes [arts. 54 y 161.1 a) CE], sin cauce propio jurisdiccional o administrativo, por no incorporar una exigencia vinculante para el destinatario". 
se hacen eco de él. Entre ellos, el de Cantabria (art. 44) y el de La Rioja (art. 45) acogen, entre sus comisiones permanentes una Comisión de peticiones «y defensa del ciudadano", y el Reglamento de la Cámara vasca atribuye la tarea a la Comisión de Urgencia Legislativa, Reglamento y Gobierno.

El Reglamento del Parlamento Vasco indica las distintas posibilidades que se abren ante una petición: trasladarlas al Defensor del Pueblo o a la Comisión del Parlamento que estuviere conociendo del asunto de que se trate; remitirlas al órgano institucional que corresponda; o archivarlas sin más trámite. "En todo caso, la Comisión acusará recibo de la petición y comunicará al peticionario, al que en casos especiales podrá dar audiencia, el acuerdo adoptado" (art. 42). En cualquier caso, estos reglamentos parecen recoger la cuestión como un asunto de trámite.

No es ese el caso de los Reglamentos de los parlamentos murciano y catalán en los que, por el contrario, además de existir comisiones cuya tarea es exclusivamente la de responder a las peticiones planteadas, además regulan de forma minuciosa las diversas vías de resolución.

\section{III.1. TitUlARIDAD}

La titularidad se atribuye a cualquier persona en el Reglamento murciano, mientras que en Cataluña habla de ciudadanos. No obstante hay que señalar que aunque la Constitución atribuye el derecho a los españoles, la L.O. 4/2001, de 12 de noviembre, reguladora del derecho de petición, lo hace a "toda persona natural o jurídica, prescindiendo de su nacionalidad", por tanto, habrá que entender que, a pesar de que el Reglamento del Parlamento catalán se refiere a ciudadanos lo hace de forma impropia y, en consecuencia, deberá admitir igualmente peticiones de extranjeros.

En los dos Reglamentos se precisa, de acuerdo con la Constitución y la L.O., que las peticiones pueden tanto tener carácter individual como colectivo, pero habrá que entender que la limitación establecida en el art. 29.2 CE para los militares (que sólo podrán ejercer este derecho de forma individual), se extiende también a las peticiones que se eleven a los parlamentos autonómicos.

\section{III.2. PRocedimiento y EFeCtos}

El Reglamento de la Asamblea de Murcia aborda tanto las cuestiones formales en torno a la presentación (peticionarios, carácter y límites de las peticiones...), como las posibles vías de resolución (art. 205 y 206 RPMur ${ }^{13}$ ).

13 Artículo 205. 1. La Comisión de Peticiones y Defensa del Ciudadano conocerá de cuantas reclamaciones y quejas dirijan a la Asamblea, individual o colectivamente, las personas con residencia en la Región de Murcia y aquellas otras que, sin tenerla, sean titulares de derechos o intereses radicados en ella y versen sobre cualquier asunto o materia comprendido en el ámbito de 
Entre esas posibles vías de resolución el Reglamento recoge que, a tenor de su multiplicidad y calado ofrecen la impresión de que se pretende no ya ofrecer

competencias de la administración de la Comunidad Autónoma. No podrán ser objeto de petición aquellos asuntos para cuya tramitación el ordenamiento jurídico establezca un procedimiento específico. 2. No serán admitidas a trámite aquellas peticiones sobre cuyo objeto exista un procedimiento parlamentario en trámite. La declaración de inadmisibilidad será notificada al peticionario haciendo mención expresa de los motivos de la misma. Contra el acuerdo de inadmisión cabrá recurso de reconsideración ante la Mesa de la Cámara, que antes de resolver definitivamente oirá a la Junta de Portavoces. 3. Las peticiones se presentarán por escrito, pudiendo utilizarse cualquier medio, incluso de carácter electrónico, que permita acreditar su autenticidad, e incluirán necesariamente la identidad del peticionario y domicilio para la práctica de notificaciones, haciendo constar, clara y razonadamente, los hechos en que aquéllas se basan, y al que se adjuntarán cuantos documentos pudieran servir para la mejor comprensión del caso. 4. Si la petición fuese colectiva, además de reunir los requisitos anteriores, será firmada por todos los peticionarios, debiendo figurar, junto a la firma de cada uno de ellos, su nombre y apellidos. 5. Si el escrito no reuniera los requisitos establecidos en este artículo o no reflejara los datos necesarios con la suficiente claridad, se requerirá al peticionario para que subsane los defectos advertidos en el plazo de quince días. De no producirse la subsanación requerida se procederá al archivo de la petición. 6. La Comisión guardará confidencialidad sobre los datos personales de los peticionarios. 7. La Comisión acusará recibo del escrito y comunicará al peticionario la decisión que, en definitiva, se adopte. 8. Si la Comisión lo estimare conveniente podrá acordar la comparecencia del interesado, al objeto de que concrete la petición o amplíe la explicación sobre los motivos que la provocan. Asimismo podrá requerir al peticionario la aportación de aquellos datos o documentos complementarios que obren en su poder o cuya obtención esté a su alcance y que resulten imprescindibles para tramitar la petición. La no aportación de tales datos o documentos determinará el archivo de la petición.

Artículo 206. 1. A la vista de las alegaciones contenidas en el escrito de petición, así como de las informaciones obtenidas, y salvo que procediere ordenar su archivo sin más trámites, la Comisión podrá: a) Utilizar cuantos medios pone este Reglamento a disposición de los Diputados, presentando a título colectivo las preguntas, mociones, proposiciones de ley y demás instrumentos que juzgue adecuados al caso. b) Dar traslado del escrito a la Comisión parlamentaria que conozca del asunto. c) Proponer al Pleno la creación de una Comisión especial para que investigue determinados hechos. d) Trasladar el asunto al Defensor del Pueblo, con la recomendación de que actúe si lo cree procedente. e) Poner los hechos en conocimiento de quien deba investigarlos y, en su caso, sancionarlos, sin que quepa archivar el expediente antes de conocer su resolución. f) Requerir al funcionario regional correspondiente para que comparezca ante la Comisión, sin que pueda vetárselo su superior jerárquico, salvo que sea para subrogarse en su lugar como compareciente. g) Comunicar las deficiencias al superior del funcionario o autoridad regional responsable de ellas, recabando traslado de su resolución. h) Acudir a cuantos medios caigan dentro del ámbito de su legitimación para actuar, y proponer los demás a quienes estén legitimados para hacerlo. 2. Las medidas anteriores podrán ser utilizadas concurrentemente, con tal de que su naturaleza lo permita. 3. Sin perjuicio de lo establecido en los dos números que anteceden, cuando la materia sobre que verse la petición no corresponda a las competencias que a la Comunidad Autónoma de Murcia asigna su Estatuto, la Comisión, si apreciare la existencia de motivos suficientes, podrá realizar cerca de los organismos competentes las gestiones que estime oportunas en demanda de colaboración. 4. De las medidas adoptadas se informará al particular interesado, y, siendo varios, al primer firmante del escrito de petición. 5 . En cada año legislativo la Comisión elevará al Pleno de la Cámara un informe acerca de sus actividades, que se publicará en el Boletín Oficial de la Asamblea Regional, y en el que, necesariamente, se hará constar: a) El número y clase de las quejas o peticiones recibidas. b) Las peticiones o quejas rechazadas, así como las que estuvieren en tramitación, y el resultado obtenido en relación con las investigadas. También podrá presentar al Pleno informes extraordinarios cuando la naturaleza o trascendencia de los hechos denunciados así lo aconsejen. 6. Al término de cada legislatura la Comisión determinará los asuntos que por no haber concluido su tramitación queden pendientes de conocimiento en la legislatura siguiente, de conformidad con lo previsto en el artículo 211. 
una mera respuesta formal al ciudadano sino tratar de resolver la petición planteada siempre que ello sea posible, ya sea, en la mayoría de los casos, por sus propios medios, ya trasladando la petición a otras instituciones, como sucede cuando recoge la posibilidad de "trasladar el asunto al Defensor del Pueblo, con la recomendación de que actúe si lo cree procedente" o "poner los hechos en conocimiento de quien deba investigarlos".

Sin embargo, como es lógico, en la mayoría de los casos lo que se plantea es una actividad de la Asamblea destinada a solucionar o al menos a dar una cumplida respuesta a la petición formulada. Así, las posibilidades que se recogen son:

- «Requerir al funcionario regional correspondiente para que comparezca ante la Comisión, sin que pueda vetárselo su superior jerárquico, salvo que sea para subrogarse en su lugar como compareciente", en este caso parece asumir funciones propias de defensor del pueblo y más allá de la comparecencia, parece que en buena parte de los casos la consecuencia será recurrir a alguna de las posibilidades de que dispone la asamblea o dar lugar a alguna del resto de las posibilidades que plantea el reglamento parlamentario en relación con las peticiones, como son las siguientes:

- Comunicar las deficiencias al superior del funcionario o autoridad regional responsable de ellas, recabando traslado de su resolución.

- Acudir a cuantos medios caigan dentro del ámbito de su legitimación para actuar, y proponer los demás a quienes estén legitimados para hacerlo.

Por otra parte, las dos primeras opciones reseñadas suponen o pueden suponer una actividad de control sobre la actividad de la administración regional, que puede dar lugar, a su vez, a la puesta en marcha de mecanismos clásicos de control como puedan ser preguntas, interpelaciones o comparecencias del gobierno de la Comunidad.

Por último, se recoge la posibilidad de proponer al Pleno la creación de una Comisión especial para que investigue determinados hechos, en definitiva, una comisión de investigación, por lo que, en este caso, ya se trataría directamente de un instrumento de control. La dificultad con la que puede plantearse es que, de acuerdo con el art. 72 del Reglamento de la Asamblea murciana, será el pleno el que decidirá acerca de la creación. La comisión de peticiones sólo efectuará la correspondiente propuesta. De esta forma, al recaer al propuesta sobre la mayoría presente en el pleno, no siempre prosperará la propuesta presentada. No obstante, si el asunto es significativo, cabe la posibilidad que, al proceder el impulso de una petición ciudadana, el pleno decida asumir el sentir de sus electores y prospere la petición, pero - como todos sabemos- las decisiones políticas podrán más que cualquier otro tipo de razón.

Junto a ello se hace contar la presentación de un informe al Pleno, que será publicado en el Boletín de la Asamblea, por lo tanto de carácter público. De 
esta forma, a pesar del carácter aparentemente restrictivo del derecho de petición, las peticiones ciudadanas pueden convertirse en una forma de control mediato del gobierno regional.

Similar opción ha adoptado el Reglamento del Parlamento de Cataluña adoptado a finales de $2005^{14}$. En él igualmente se recogen, entre otras las posibilidades: a) acordar la comparecencia no sólo del gobierno, de autoridades públicas o de las administraciones públicas, sino también de personas y organizaciones ciudadanas; trasladar la petición al Sindic de Greuges ${ }^{15}$, para que proceda de acuerdo con lo establecido en su ley de desarrollo; c) asumir el contenido de las peticiones presentadas y formular recomendaciones sobre éstas a los poderes públicos y a las instituciones.

También en este caso se establece la presentación de una memoria de actividades al Pleno.

Tanto en el parlamento de Murcia como en el de Cataluña se aprecia con claridad que el ejercicio del derecho de petición, puede tener un alcance mucho más incisivo que ofrecer una mera respuesta al ciudadano, puesto que, en ambos casos, la petición ciudadana puede dar lugar a poner en marcha mecanismos de control, cuyo alcance queda en manos de los propios parlamentos y de los instrumentos de que los dotan sus Reglamentos.

En el caso de ejercicio del derecho de petición también cabe el recurso de amparo ante el Tribunal Constitucional por parte del peticionario, como lo ponen de relieve los casos citados, aunque el alcance del fallo se limite a reconocer el derecho a obtener una respuesta y a gozar de indemnidad en el ejercicio del citado derecho. El recurso se plantearía por la vía del art. 42 LOTC al tratarse de un acto de una Cámara parlamentaria.

14 Art. 60 del Reglamento del Parlamento de Cataluña. 1.La Comissió de Peticions és l'òrgan competent per a tramitar les peticions que els ciutadans fan al Parlament en l'exercici del dret de petició individual o col.lectiva. La composició i el funcionament de la Comissió s'han d'ajustar a allò que estableix l'article 40 i els concordants. 2. La Comissió de Peticions ha d'examinar cada petició que rebi el Parlament. A proposta d'un grup parlamentari pot convocar els peticionaris perquè informin sobre els aspectes de la petició que consideri pertinents. 3. una vegada examinada la petició, la Comissió de Peticions, per conducte de la presidència, pot acordar de remetre-la: a) A la comissió parlamentària competent per raó de la matèria de què es tracti, que l'haurà d'informar dels punts sol.licitats. b) Al grups parlamentaris, perquè, si lo creuen convenient, puguin promoure alguna iniciativa parlamentària. c) Al Govern o als departaments competents per raó de la matèria, amb la sol.licitud, si escau, d'explicacions sobre el contingut de la petició. d) A qualsevol altre òrgan de la Generalitat, d'altres administracions públiques, autoritats i institucions, amb la sol.licitud d'informació que consideri pertinent. e) Al Síndic de Greuges, als efectes establerts per la llei corresponent. 4. La Comissió de Peticions, quan ho consideri convenient en la tramitació d'una petició, pot acordar la compareixença de persones i organitzacions ciutadanes. 5. La Comissió de Peticions pot adoptar resolucions que assumeixin el contingut de les peticions presentades i pot formular recomanacions sobre aquestes als poders públics i a les institucions. 6. La Comissió de Peticions, un cop examinada una petició, també en pot acordar l'arxivament sense cap més tràmit, en el cas que la remissió a què es refereix l'aparta 3 no sigui procedent. 7. En tots els casos, la Comissió de Peticions ha d'acusar la recepció de cada petició i, en el termini de tres mesos d'ençà de la presentació d'una petició, ha de comunicar els acords adoptats als peticionaris. 8. La Comissió de Peticions ha de presentar al Ple del Parlament una memòria anual sobre les seves activitats.

15 La Comunidad cuenta con institución de este tipo propia. 
En su caso, aquí la posibilidad de un ulterior recurso por parte de un parlamentario no se vincularía ya al derecho de petición (el cual parece reducir su legitimación activa al propio peticionario o, en su caso, al Ministerio Fiscal o al Defensor del Pueblo), sino al artículo 23 CE, en relación con las estipulaciones del correspondiente Reglamento parlamentario y de acuerdo con los mecanismos por los que hubiera optado la Cámara, de tal forma que el objeto de un hipotético recurso sería distinto de plantearlo el peticionario a hacerlo un diputado.

Las peticiones ciudadanas pueden ser un buen medio para conocer la actividad de la administración regional o las consecuencias de las medidas de los órganos de la comunidad y de esta forma un buen medio para que los diputados conozcan las deficiencias existentes.

\section{CONCLUSIONES}

Los Parlamentos deben hacer un esfuerzo por abrirse a sus ciudadanos y los diputados han de establecer una mayor y mejor relación con los electores. Los parlamentos autonómicos deberían ser cauce participativo no sólo de representantes, sino del conjunto de los ciudadanos. Los modos de participación a los que hemos hechos referencia deberían ser sólo la punta de lanza de unos modelos más participativos, en los que la atención de los ciudadanos volviera al parlamento. El acercamiento a la sociedad no puede recaer sólo en al creación de páginas web o de presenciar en directo a través de Internet las sesiones parlamentarias. Que los ciudadanos se interesen por sus asambleas pasa por crear y fomentar mecanismos de participación directa, viables, precisamente en el ámbito autonómico.

Por otra parte, tanto las preguntas ciudadanas como las peticiones pueden ser un mecanismo idóneo para que los diputados conozcan mejor el estado de su comunidad y, en relación con éste, la actuación del ejecutivo y de la administración autonómica y así, a su vez, les sirvan para acercar el control a los ciudadanos, que el control parlamentario sea no sólo una "representación" (o presentación) de los partidos políticos, alejada muchas veces de los intereses de los ciudadanos, sino un instrumento vivo. Por último, ¿qué mejor control que el que se deriva directamente de quienes padecen las políticas públicas? ¿qué mejor medio para conocer su impacto que la expresión directa por los ciudadanos?

En definitiva, la representación puede hacerse más cercana si se presta la atención debida a la voz de los ciudadanos.

ABstract. The Parliaments of 'Comunidades Autonomas' (Self-Governing Communities) adopted some new forms of political control. One of these are citizenship questions, that we can find in the Standings Orders of the 
Parliaments of Andalusia, Murcia and Canary Inlands. This kind of questions are proposed by citizens and then have to be submitted by a member of Parliament, then the procedure is the same than the ordinary questions. Thus citizens are admitted in parliamentary procedures. The traditional right of petition, like expressed in some Standing Orders, specially in Murcia and Catalonia, also can provide some sort of control over Cabinet, because it can start different mechanisms of control inside or outside Parliament (ad hoc committees, appearance of members of Government...). Citizenship questions and petitions show that are possible new ways in parliamentary life, which provide new and better citizens' participation. 